University of Nebraska - Lincoln

DigitalCommons@University of Nebraska - Lincoln

Faculty Publications from the Department of Electrical \& Computer Engineering, Department Electrical and Computer Engineering

2009

\title{
Real-Time Implementation of a STATCOM on a Wind Farm Equipped With Doubly Fed Induction Generators
}

\author{
Wei Qiao \\ University of Nebraska-Lincoln, wqiao@engr.unl.edu \\ Ganesh Kumar Venayagamoorthy \\ Missouri University of Science and Technology \\ Ronald G. Harley \\ Georgia Institute of Technology
}

Follow this and additional works at: https://digitalcommons.unl.edu/electricalengineeringfacpub

Part of the Electrical and Computer Engineering Commons

Qiao, Wei; Venayagamoorthy, Ganesh Kumar; and Harley, Ronald G., "Real-Time Implementation of a STATCOM on a Wind Farm Equipped With Doubly Fed Induction Generators" (2009). Faculty Publications from the Department of Electrical and Computer Engineering. 134.

https://digitalcommons.unl.edu/electricalengineeringfacpub/134

This Article is brought to you for free and open access by the Electrical \& Computer Engineering, Department of at DigitalCommons@University of Nebraska - Lincoln. It has been accepted for inclusion in Faculty Publications from the Department of Electrical and Computer Engineering by an authorized administrator of DigitalCommons@University of Nebraska - Lincoln. 


\title{
Real-Time Implementation of a STATCOM on a Wind Farm Equipped With Doubly Fed Induction Generators
}

\author{
Wei Qiao, Member, IEEE, Ganesh Kumar Venayagamoorthy, Senior Member, IEEE, and \\ Ronald G. Harley, Fellow, IEEE
}

\begin{abstract}
Voltage stability is a key issue to achieve the uninterrupted operation of wind farms equipped with doubly fed induction generators (DFIGs) during grid faults. This paper investigates the application of a static synchronous compensator (STATCOM) to assist with the uninterrupted operation of a wind turbine driving a DFIG, which is connected to a power network, during grid faults. The control schemes of the DFIG rotor- and grid-side converters and the STATCOM are suitably designed and coordinated. The system is implemented in real-time on a Real Time Digital Simulator. Results show that the STATCOM improves the transient voltage stability and therefore helps the wind turbine generator system to remain in service during grid faults.
\end{abstract}

Index Terms-Doubly fed induction generators (DFIGs), real-time implementation, static synchronous compensator (STATCOM), wind turbine.

\section{INTRODUCTION}

$\mathbf{T}$ HE WORLDWIDE concern about environmental pollution and a possible energy shortage has led to increasing interest in technologies for the generation of renewable electrical energy. Among various renewable energy sources, wind power is the most rapidly growing one in Europe and the United States.

With the recent progress in modern power electronics, the concept of a variable-speed wind turbine (VSWT) equipped with a doubly fed induction generator (DFIG) is receiving increasing attention because of its advantages over other wind

Paper MSDAD-07-80, presented at the 2006 Industry Applications Society Annual Meeting, Tampa, FL, October 8-12, and approved for publication in the IEEE TRANSACTIONS ON INDUSTRY APPLICATIONS by the Industrial Automation and Control Committee of the IEEE Industry Applications Society. Manuscript submitted for review November 30, 2006 and released for publication April 23, 2008. Current version published January 21, 2009. This work was supported in part by the National Science Foundation under Grant ECS 0524183 and in part by Duke Power Company, Charlotte, NC.

W. Qiao is with the Department of Electrical Engineering, University of Nebraska-Lincoln, Lincoln, NE 68588-0511 USA (e-mail: wqiao@engr. unl.edu).

G. K. Venayagamoorthy is with the Real-Time Power and Intelligent Systems Laboratory, Department of Electrical and Computer Engineering, Missouri University of Science and Technology, Rolla, MO 65409-0249 USA (e-mail: gkumar@ieee.org).

R. G. Harley is with the Intelligent Power Infrastructure Consortium, School of Electrical and Computer Engineering, Georgia Institute of Technology, Atlanta, GA 30332-0250 USA (e-mail: rharley@ece.gatech.edu).

Color versions of one or more of the figures in this paper are available online at http://ieeexplore.iee.org.

Digital Object Identifier 10.1109/TIA.2008.2009377 turbine generator concepts [1]-[4]. In the DFIG concept, the induction generator is grid-connected at the stator terminals; the rotor is connected to the utility grid via a partially rated variable frequency ac/dc/ac converter (VFC), which only needs to handle a fraction $(25 \%-30 \%)$ of the total DFIG power to achieve full control of the generator. The VFC consists of a rotor-side converter (RSC) and a grid-side converter (GSC) connected back-to-back by a dc-link capacitor.

When connected to the grid and during a grid fault, the RSC of the DFIG may be blocked to protect it from overcurrent in the rotor circuit [1], [3], [4]. The wind turbine typically trips shortly after the converter has blocked and automatically reconnects to the power network after the fault has cleared and the normal operation has been restored. In [1], the author proposed an uninterrupted operation feature of a DFIG wind turbine during grid faults. In this feature, the RSC is blocked, and the rotor circuit is short-circuited through a crowbar circuit (an external resistor); the DFIG becomes a conventional induction generator and starts to absorb reactive power. The wind turbine continues its operation to produce some active power, and the GSC can be set to control the reactive power and voltage at the grid connection. The pitch angle controller might be activated to prevent the wind turbine from fatal overspeeding. When the fault has cleared and when the voltage and the frequency in the utility grid have been reestablished, the RSC will restart, and the wind turbine will return to normal operation. However, in the case of a weak power network and during a grid fault, the GSC cannot provide sufficient reactive power and voltage support due to its small power capacity, and there can be a risk of voltage instability. As a result, utilities, typically, immediately disconnect the wind turbines from the grid to prevent such a contingency and reconnect them when normal operation has been restored. Therefore, voltage stability is the crucial issue in maintaining uninterrupted operation of wind turbines equipped with DFIGs [1]. With the rapid increase in penetration of wind power in power systems, tripping of many wind turbines in a large wind farm during grid faults may begin to influence the overall power system stability. It has been reported recently [5] that integration of wind farms into the East Danish power system could cause severe voltage recovery problems following a three-phase fault on that network.

The problem of voltage instability can be solved by using dynamic reactive compensation. Shunt flexible ac transmission system (FACTS) devices, such as the static var compensator 
TABLE I

SYSTEM PARAMETERS (ON 3.6-MW 4.16-kV BASES)

\begin{tabular}{|c|c|c|c|c|c|}
\hline \multicolumn{2}{|c|}{ Wind turbine } & \multicolumn{2}{c|}{ Induction generator } & \multicolumn{2}{l|}{ Power network } \\
\hline Rated capacity & $3.6 \mathrm{MW}$ & $P_{\text {rated }}$ & $3.6 \mathrm{MW}$ & $r_{l 1}$ & 0.14 \\
\hline Cut-in wind speed & $3.5 \mathrm{~m} / \mathrm{s}$ & $V_{\mathrm{s}, \text { rated }}$ & $4.16 \mathrm{kV}$ & $x_{l 1}$ & 0.8 \\
\hline Cut-out wind speed & $27 \mathrm{~m} / \mathrm{s}$ & $r_{s}$ & 0.0079 & $r_{l 2}$ & 0.14 \\
\hline Rated wind speed & $14 \mathrm{~m} / \mathrm{s}$ & $r_{r}$ & 0.025 & $x_{l 2}$ & 0.8 \\
\hline Number of blades & 3 & $L_{l s}$ & 0.07939 & $Z_{L}$ & $0.7+j 1.5$ \\
\hline Rotor diameter & $104 \mathrm{~m}$ & $L_{l r}$ & 0.40 & & \\
\hline Swept area & $8495 \mathrm{~m}^{2}$ & $L_{m}$ & 4.4 & & \\
\hline Rotor speed & $8.5-15.3 \mathrm{rpm}$ & $p f$ & $-0.9 \sim+0.9$ & & \\
\hline
\end{tabular}

(SVC) and the static synchronous compensator (STATCOM), have been widely used to provide high-performance steadystate and transient voltage control at the point of common coupling (PCC) [6]. The application of an SVC or a STATCOM to a wind farm equipped with fixed-speed wind turbines (FSWTs) and squirrel-cage induction generators (SCIGs) has been reported in [7] and [8] for steady-state voltage regulation and in [1] and [8] for short-term transient voltage stability. However, compared with the FSWT with a SCIG, the operation of the VSWT with a DIFG, particularly during grid faults, is more complicated due to the use of power electronic converters, and it has not yet been studied with the use of dynamic reactive compensation.

This paper investigates the application of a STATCOM to help with the uninterrupted operation of a VSWT equipped with a DFIG during grid faults. The STATCOM is shunt connected at the bus where the wind turbine is connected to the power network to provide steady-state voltage regulation and improve the short-term transient voltage stability. The DFIG and STATCOM control schemes are suitably designed and coordinated. The system is implemented in real-time on a Real Time Digital Simulator (RTDS).

\section{Power Network Model}

In a real power system, a large wind farm generally consists of hundreds of individual wind turbines. It has been reported in [1] that with well-tuned converters, there is no mutual interaction between wind turbines in a wind farm, independently from the conditions of the power grid. Therefore, in this paper, only one wind turbine is used to represent the wind farm.

Fig. 1 shows the single-line diagram of the power system used for this paper. In a real power system, a large power plant is normally connected to the power network by multiple parallel power lines with certain capacity redundancy, not only because of the thermal limits of each single power line but also to increase the reliability of the power transmission in the case of the outage of one power line. As in this paper, a 3.6-MW DFIG driven by a wind turbine [9] is connected to a power grid through a transformer and two parallel lines. A three-phase balanced electric load at the sending end bus is modeled as a constant impedance load $Z_{L}$. A STATCOM is shunt connected at the sending end bus for steady-state, as well as transient, voltage support. The parameters of the system components are given in Table I.

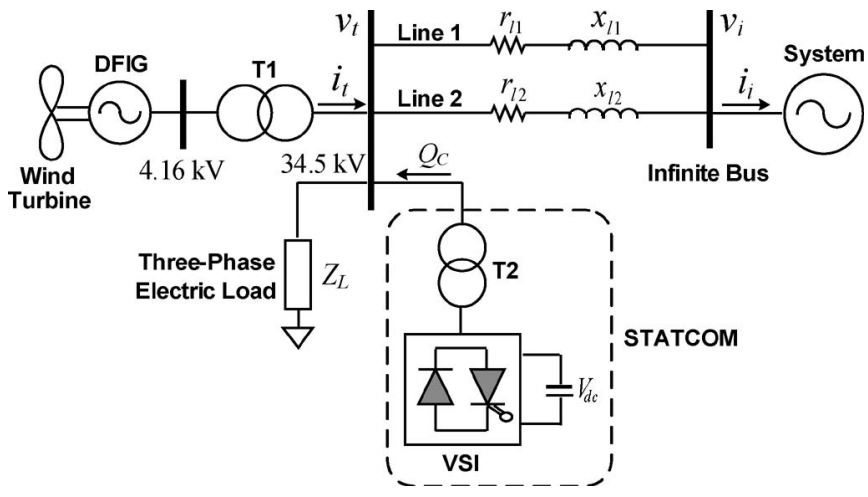

Fig. 1. Single-line diagram of the power network.

\section{Modeling And Control of DFIG}

The basic configuration of a DFIG driven by a wind turbine is shown in Fig. 2. The wind turbine is connected to the DFIG through a mechanical shaft system, which consists of a lowand a high-speed shaft with a gearbox in between. The woundrotor induction machine in this configuration is fed from both stator and rotor sides. The stator is directly connected to the grid while the rotor is connected to the grid through a VFC. In order to produce electrical power at constant voltage and frequency to the utility grid for a wide operating range from subsynchronous to supersynchronous speeds, the power flow between the rotor circuit and the grid must be controlled both in magnitude and in direction. Therefore, the VFC consists of two four-quadrant insulated-gate bipolar transistor (IGBT) pulse width modulation (PWM) converters connected back-toback by a dc-link capacitor [10]. The crowbar is used to shortcircuit the RSC in order to protect it from overcurrent in the rotor circuit during transient grid disturbances.

Control of the DFIG is achieved by control of the VFC, which includes control of the RSC [4], [10]-[12] and control of the GSC [10]. The objective of the RSC is to independently regulate the stator active and reactive powers, which are represented by $P_{s}$ and $Q_{s}$, respectively. The reactive-power control using the RSC can be applied to keep the stator voltage $V_{s}$ within the desired range, when the DFIG feeds into a weak power system without any local reactive compensation. When the DFIG feeds into a strong power system, the command of $Q_{s}$ can be simply set to zero. Fig. 3 shows the overall vector control scheme of the RSC. In order to achieve independent control of the stator active power $P_{s}$ and reactive power $Q_{s}$ (Fig. 2) by means of rotor current regulation, the instantaneous three-phase rotor currents $i_{r a b c}$ are sampled and transformed to $d-q$ components $i_{d r}$ and $i_{q r}$ in the stator-flux-oriented reference frame. The reference values of $i_{d r}$ and $i_{q r}$ can be determined directly from $Q_{s}$ and $P_{s}$ commands, respectively. The actual $d-q$ current signals $\left(i_{d r}\right.$ and $\left.i_{q r}\right)$ are then compared with their reference signals $\left(i_{d r}^{*}\right.$ and $\left.i_{q r}^{*}\right)$ to generate the error signals, which are passed through two PI controllers to form the voltage signals $\nu_{d r 1}$ and $\nu_{q r 1}$. The two voltage signals $\left(\nu_{d r 1}\right.$ and $\left.\nu_{q r 1}\right)$ are compensated by the corresponding cross-coupling terms $\left(\nu_{d r 2}\right.$ and $\nu_{q r 2}$ ) to form the $d-q$ voltage signals $\nu_{d r}$ and $\nu_{q r}$. These are then used by the PWM module to generate the IGBT gate control signals to drive the rotor-side IGBT converter. 


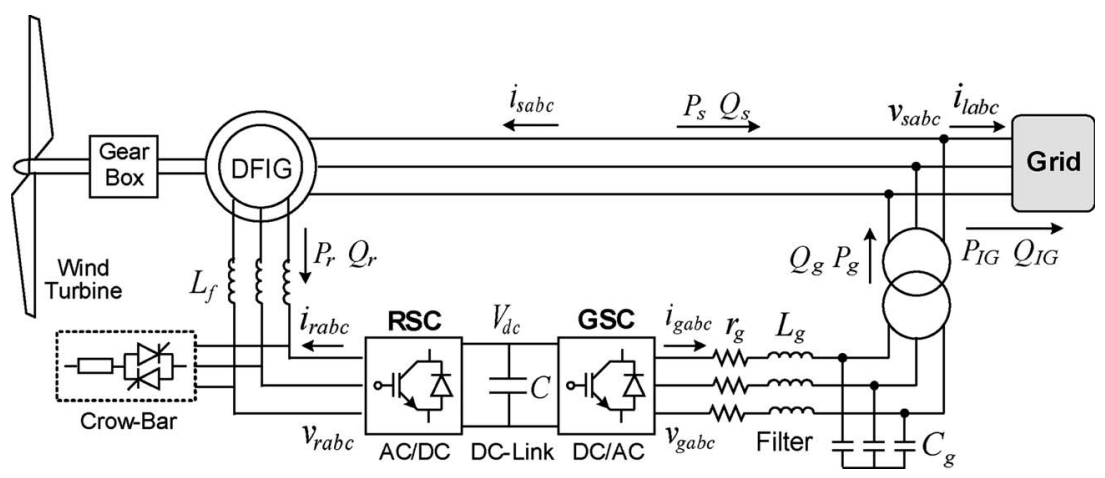

Fig. 2. Configuration of a DFIG wind turbine.

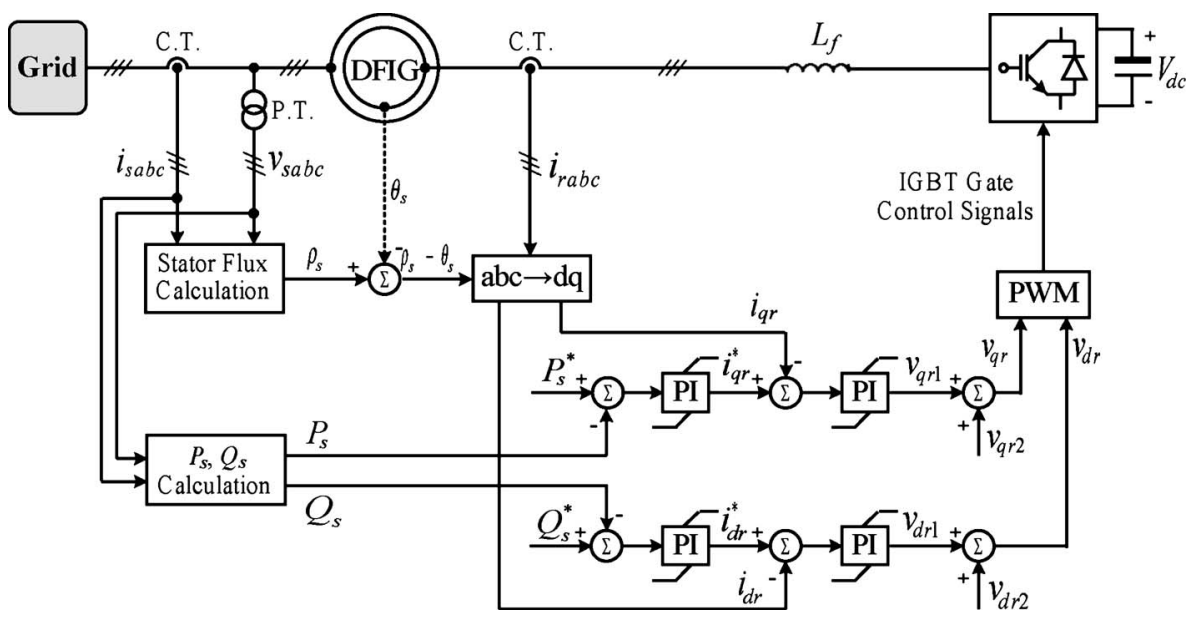

Fig. 3. Overall control scheme of the RSC. $\nu_{d r 2}=-s \omega_{s} \sigma L_{r} i_{q r} ; \nu_{q r 2}=s \omega_{s}\left(\sigma L_{r} i_{d r}+L_{m}^{2} i_{m s} / L_{s}\right)$.

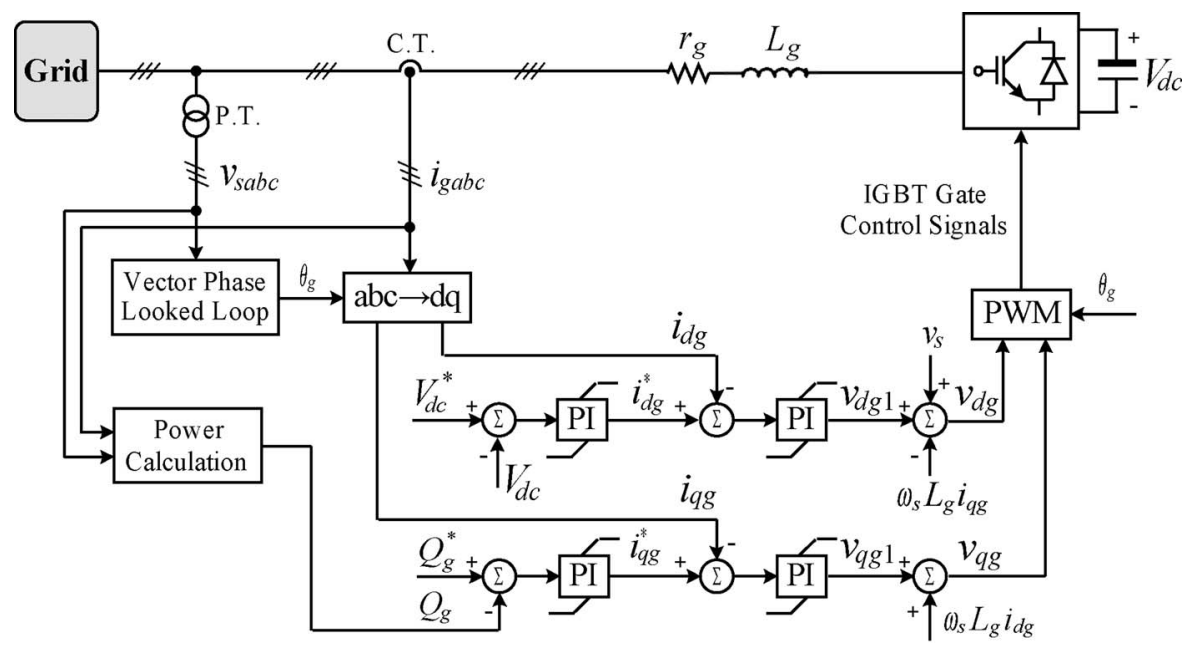

Fig. 4. Overall control scheme of the GSC.

The objective of the GSC is primarily to keep the dc-link voltage constant regardless of the magnitude and direction of the rotor power. In this paper, the GSC control scheme is also designed to regulate the reactive power $Q_{g}$ exchanged between the GSC and the grid. During normal operation, the GSC is considered to be reactive neutral by setting $Q_{g}^{*}=0$. This consideration is reasonable because the VFC rating is only $25 \%-30 \%$ of the generator rating and because the VFC is primarily used to supply the active power from the rotor to the power grid. However, the reactive-power controllability of the GSC can be useful during the process of voltage reestablishment, after a grid fault has been cleared and the RSC has been blocked. Fig. 4 shows the overall control scheme of the GSC. The actual signals of the dc-link voltage and the reactive power $\left(V_{d c}\right.$ and $\left.Q_{g}\right)$ are compared with their command values $\left(V_{d c}^{*}\right.$ and $Q_{g}^{*}$ ) to form the error signals, which are passed through the PI controllers to generate the reference signals for the $d$ and $q$-axes' current components $\left(i_{d g}^{*}\right.$ and $i_{q g}^{*}$ ), respectively. 


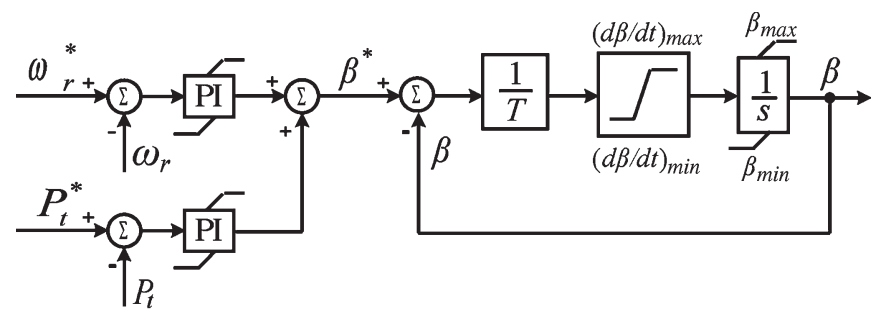

Fig. 5. Wind-turbine pitch angle controller.

The instantaneous ac-side three-phase currents of the GSC are sampled and transformed into $d-q$ current components $i_{d g}$ and $i_{q g}$ by applying the synchronously rotating reference frame transformation. The actual signals $\left(i_{d g}\right.$ and $\left.i_{q g}\right)$ are then compared with the corresponding reference signals to form the error signals, which are passed through two PI controllers. The voltage signals $\left(\nu_{d g 1}\right.$ and $\left.\nu_{q g 1}\right)$ are compensated by the corresponding cross-coupling terms to form the $d-q$ voltage signals $\nu_{d g}$ and $\nu_{q g}$. They are then used by the PWM module to generate the IGBT gate control signals to drive the grid-side IGBT converter.

\section{WIND-TURBINE MODEL}

The aerodynamic model of a wind turbine can be characterized by the well-known $C_{P}-\lambda-\beta$ curves. $C_{P}$ is called power coefficient, which is a function of both tip-speed ratio $\lambda$ and the blade pitch angle $\beta$. The tip-speed ratio $\lambda$ is defined by

$$
\lambda=\omega_{t} R / \nu_{w}
$$

where $R$ is the blade length in meters, $\omega_{t}$ is the wind-turbine rotor speed in radians per second, and $\nu_{w}$ is the wind speed in meters per second. The $C_{P}-\lambda-\beta$ curves depend on the blade design and are given by the wind-turbine manufacturer. Given the power coefficient $C_{P}$, the mechanical power extracted by the turbine from the wind is calculated by [1], [9]

$$
P_{m}=\frac{1}{2} \rho A_{r} \nu_{w}^{3} C_{P}(\lambda, \beta)
$$

where $\rho$ is the air density in kilograms per cubic meter; $A_{r}=$ $\pi R^{2}$ is the area in square meters swept by the rotor blades.

At a specific wind speed, there is a unique value of $\omega_{t}$ to achieve the maximum power coefficient $C_{P}$ and thereby extract the maximum mechanical (wind) power. If the wind speed is below the rated (maximum) value, the wind turbine operates in the variable-speed mode, and the rotational speed is adjusted (by means of active-power control in the DFIG) such that the maximum value of $C_{P}$ is achieved. In this operating mode, the wind turbine pitch control is deactivated, and the pitch angle $\beta$ is fixed. If the wind speed is above the rated value, the rotor speed can no longer be controlled within the limits by increasing the generated power, as this would lead to overloading of the generator and/or the converter. In such a situation, the pitch control is activated to increase the wind turbine pitch angle to reduce the mechanical power extracted from the wind. Fig. 5 shows the structure of the pitch angle controller [1], [9]. $P_{t}\left(=P_{s}+P_{r}\right)$ is the total output active power from the DFIG.

\section{STATCOM MODEL}

A STATCOM [6], [13], also known as an advanced SVC, is a shunt-connected FACTS device. It generates a set of balanced three-phase sinusoidal voltages at the fundamental frequency, with rapidly controllable amplitude and phase angle. A typical application of a STATCOM is for voltage support. In this paper, the STATCOM is modeled as a gate turn-off thyristor (GTO) PWM converter with a dc-link capacitor. The objective of the STATCOM is to rapidly regulate the voltage at the PCC in the desired range. It can enhance the capability of the wind turbine to ride through transient disturbances in the grid. The overall control scheme of the STATCOM is shown in Fig. 6.

\section{UNINTERRUPTED OPERATION FEATURE OF THE Wind TURBINE DURING GRID FAULTS}

The idea behind this uninterrupted operation feature is that the wind turbine does not trip when the RSC has blocked during a grid fault. During the RSC blocking, the rotor circuit is short-circuited by a crowbar, which is simply implemented by connecting an external resistor across each phase of the rotor circuit. The value of the external resistance is chosen as $R_{\text {ext }}=20 \cdot r_{r}$, as recommended in [14]. The wind turbine continues its operation, with the DFIG rotor short-circuited. During such an operating condition, the controllability of the RSC is naturally lost, and there is no longer any independent control of active and reactive powers in the DFIG. The DFIG becomes a conventional induction generator, which produces an amount of active power and starts to absorb an amount of reactive power. In order to prevent the wind turbine from overspeeding, the pitch angle controller can be activated to keep the speed around the predefined value.

When the RSC is blocking, the GSC can be set to control the reactive power exchanged between the DFIG and the grid. This controllability of the GSC, however, is limited due to the small capacity of the converter. In a weak power network, as a result, there can be a risk of voltage instability and the subsequent tripping of the wind turbine generator. To avoid such a contingency, a STATCOM is used to provide transient voltage support to help the DFIG ride through grid faults. The STATCOM can also be used for steady-state voltage regulation and power factor control of the DFIG.

During the RSC blocking, the RSC control system continues monitoring the rotor current, the terminal voltage, the active and reactive powers, and the generator rotor speed. When the fault has cleared and when the terminal voltage and the rotor current return to their predefined ranges, the RSC starts synchronization [1]. At synchronization, the RSC starts switching, and the external resistance is disconnected; the $d-q$ components of the RSC voltage source (Fig. 3) are set to $\nu_{d r}=i_{d r} \cdot R_{\text {ext }}$ and $\nu_{q r}=$ $i_{q r} \cdot R_{\text {ext }}$, which are used by the PWM module to generate the IGBT gate control signals to drive the IGBT converter. When the synchronization seems to be complete, the control system of the RSC switches to the regular control system, as shown in Fig. 3, and the RSC restarts. When the RSC has restarted, the DFIG again has independent active- and reactive-power controls, and the wind turbine returns to normal operation. 


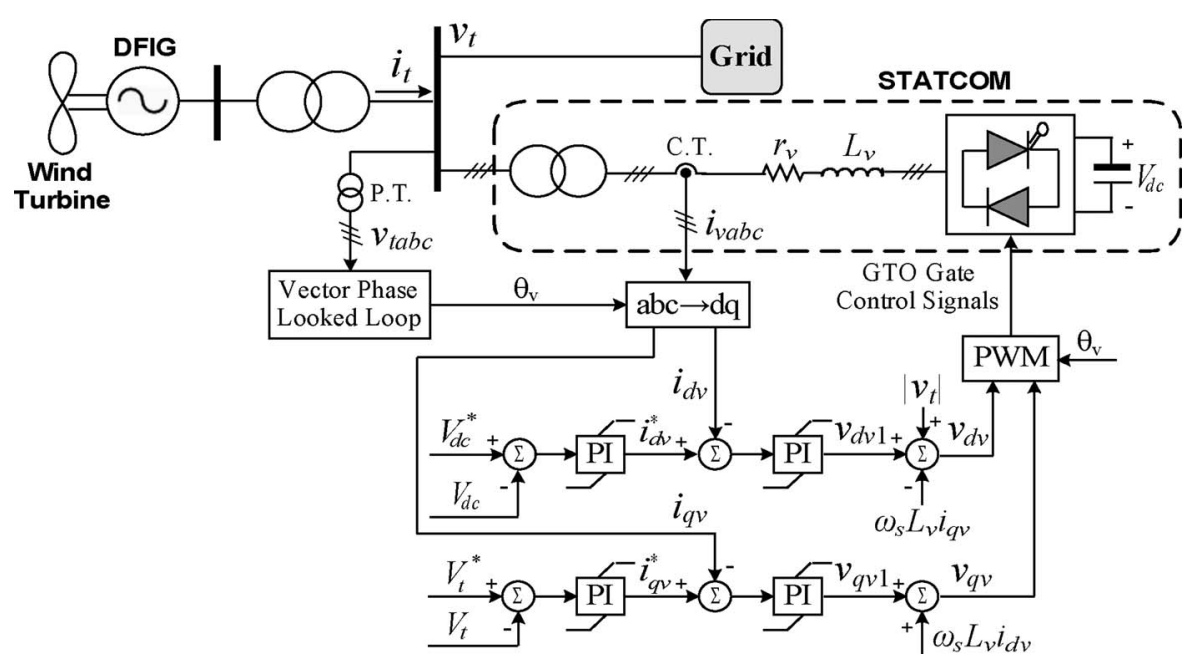

Fig. 6. Overall control scheme of the STATCOM.

The advantages of this uninterrupted operation feature include the following: 1) The wind turbine continues supplying the active power to the power network, and therefore, the demand for immediate power reserves is reduced, and 2) the wind turbine can contribute to maintaining the frequency in the power network during a transient state.

\section{REAL-Time IMPLEMENTATION SETUP}

The RTDS is a fully digital electromagnetic transient power system simulator capable of continuous, sustained real-time operation [15], i.e., it can solve the power system equations fast enough to continuously produce output conditions that realistically represent conditions in the real network. The RTDS has been widely accepted as an ideal tool for the design, development, and testing of power system protection and control schemes. Considering that the solution is in real time, it can be connected directly to the power system control and protective relay components.

The RTDS is a combination of advanced computer hardware and comprehensive software, as shown in Fig. 7. It has a custom parallel-processing hardware architecture assembled in modular units called racks. Each rack contains both processing and communication modules. The mathematical computations for individual power system components and for network equations are performed using processor modules. The RTDS uses a userfriendly graphical interface - the RSCAD Software Suite-as the user's main interface with the RTDS hardware. The software is comprised of several modules designed to allow the user to easily perform all of the necessary steps to prepare and run a simulation and to analyze simulation output.

The RTDS hardware has a number of different types of processor cards available, including the Triple Processor Cards (3PCs), the RISC Processor Card (RPC), and the Giga Processor Card (GPC). The 3PC contains three Analog Device ADSP21062 (SHARC) processors, each operating at $80 \mathrm{MHz}$. The 3PC is typically used to perform the computations required to model the user's power system and control systems with a typical time step of $50 \mu \mathrm{s}$. The RPC contains two IBM PowerPC 750CXe RISC processors, each operating at $600 \mathrm{MHz}$. The

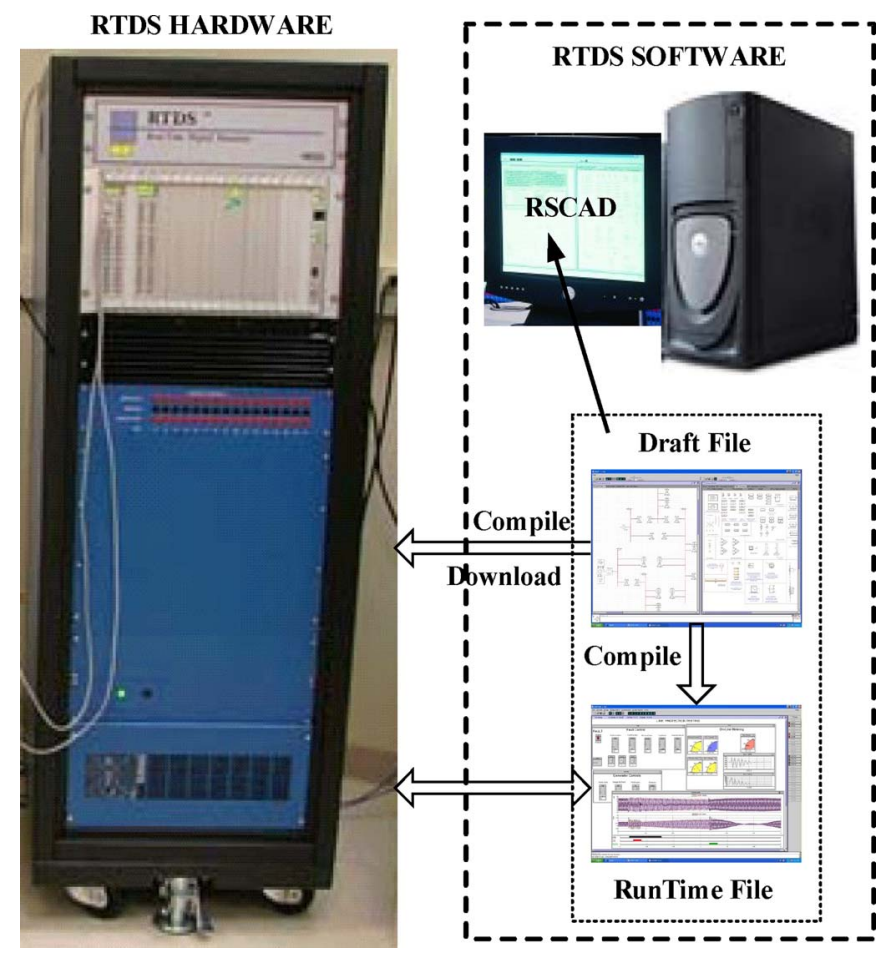

Fig. 7. Real-time implementation setup using RTDS.

most recent GPC contains two IBM PowerPC 750GX RISC processors, each operating at $1 \mathrm{GHz}$. In addition to the network solution and the simulation of standard components, the GPC can also be used to provide small timestep $(<2 \mu \mathrm{s})$ simulations of voltage source converters with a high switching frequency. The RTDS provides a specially designed small- $d t$ module to perform the small timestep simulations on the GPC card. In this paper, the VFC of the DFIG contains two PWM IGBT converters with switching frequencies of $2 \mathrm{kHz}$ each and therefore is simulated on the GPC card using the small- $d t$ module. The power network model and the STATCOM are simulated on the 3PC and RPC cards, respectively. The control systems are simulated on the 3 PC cards. Fig. 8 shows the RTDS modules and the processor assignments for a real-time implementation of the system in Fig. 1. In RTDS, an interface transformer 


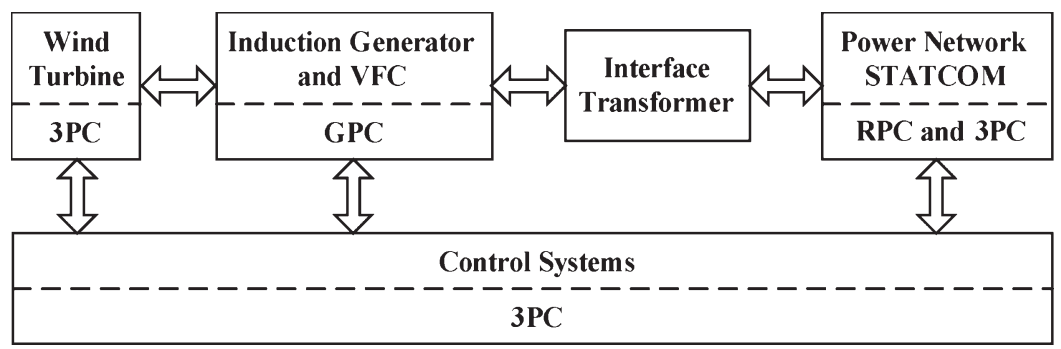

Fig. 8. RTDS modules and processor assignments for real-time implementation.

is used to connect the small-timestep power system module $(<2 \mu \mathrm{s})$ to the large-timestep $(50 \mu \mathrm{s})$ power system module.

\section{REAL-TIME IMPLEMENTATION RESULTS}

This section presents the real-time implementation results of the system in Fig. 1 at the following operating conditions: 1) The wind speed is constant during the simulation (this assumption is reasonable for investigating short-term voltage stability [1]); 2) the DFIG is running at a supersynchronous speed with the generator rotor speed at about 1.2 per unit (p.u.); and 3) the DFIG does not exchange reactive power with the power system when applying the STATCOM, namely, the reactive power commands of both RSC and GSC are set to zero.

\section{A. Steady-State Voltage Regulation}

The voltage command of the STATCOM controller $V_{t}^{*}$ (Fig. 6) is step changed from 0.92 to 1.02 p.u. at $t=2 \mathrm{~s}$ and back to 0.92 p.u. at $t=5$ s. Fig. 9 shows the steady-state voltage regulation result and the corresponding reactive power $Q_{c}$ compensated by the STATCOM. Without any reactive compensation, the initial steady-state value of the PCC voltage $V_{t}$ (Fig. 1) is 0.92 p.u., which is below the lower limit value of 0.95 p.u. With the STATCOM inserted for reactive compensation, the PCC voltage is kept at the desired value of 1.02 p.u. The response of the STATCOM to the step change of the voltage command is fast and smooth.

\section{B. Three-Phase Short Circuit Test: RSC Not Blocking}

Grid faults, even if far away from the location of the wind turbine, can cause voltage sags at the connection point of the wind turbine. Such a voltage sag results in an imbalance between the turbine input power and the generator output power, which initiates the machine stator and rotor current transients, the converter current transient, the dc-link voltage fluctuations, and a change in speed.

A temporary three-phase short circuit is applied for $200 \mathrm{~ms}$ to the infinite bus in Fig. 1 at $t=2 \mathrm{~s}$. The protective system of the wind turbine and the DFIG is disabled in this test. Fig. 10 shows the rotor current $I_{r}$ response with and without the STATCOM. In the case of no STATCOM, the reactive power command of the RSC is set to 0.28 p.u. in order to regulate the PCC voltage at 1.02 p.u. These results show that during the fault and postfault transient states, the rotor current exceeds its limit value $(1.0 \mathrm{kA})$ in both cases. Therefore, the RSC must be blocked to avoid being destroyed by the overcurrent in the rotor circuit.

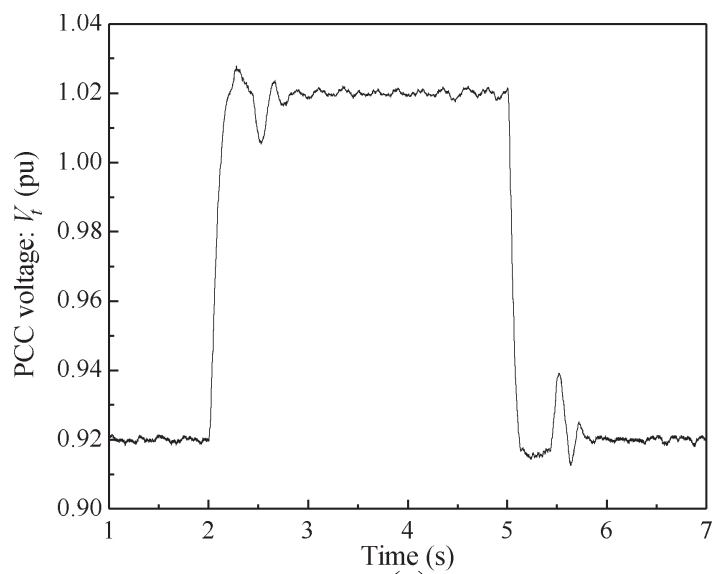

(a)

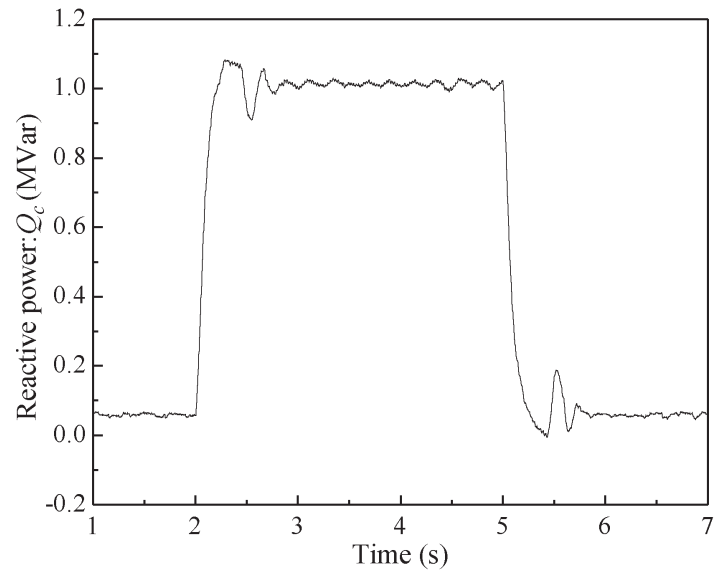

(b)

Fig. 9. Steady-state voltage regulation result of STATCOM at PCC: $V_{t}$ and $Q_{c}$, when the reference $V_{t}^{*}$ has a step change.

\section{Three-Phase Short Circuit Test Without the STATCOM: RSC Blocking}

The same three-phase short circuit test as in Fig. 10 is applied at $t=2 \mathrm{~s}$ without using the STATCOM; this time, however, $30 \mathrm{~ms}$ after applying the fault (at $t=2.03 \mathrm{~s}$ ), the RSC is blocked to protect it from overcurrent in the rotor circuit. Fig. 11 shows the voltage profiles at the PCC. The curve GSC indicates the result with the reactive compensation by the GSC (the reactive power command of the GSC is set to the maximum value of 0.25 p.u. instead of zero) from $2.03 \mathrm{~s}$, and the curve $\mathrm{NC}$ indicates the result without any reactive compensation from $2.03 \mathrm{~s}$. In both cases of GSC and $\mathrm{NC}$, the reactive power command of the RSC is set to 0.28 p.u. instead of zero before applying the fault in order to regulate the PCC voltage at 


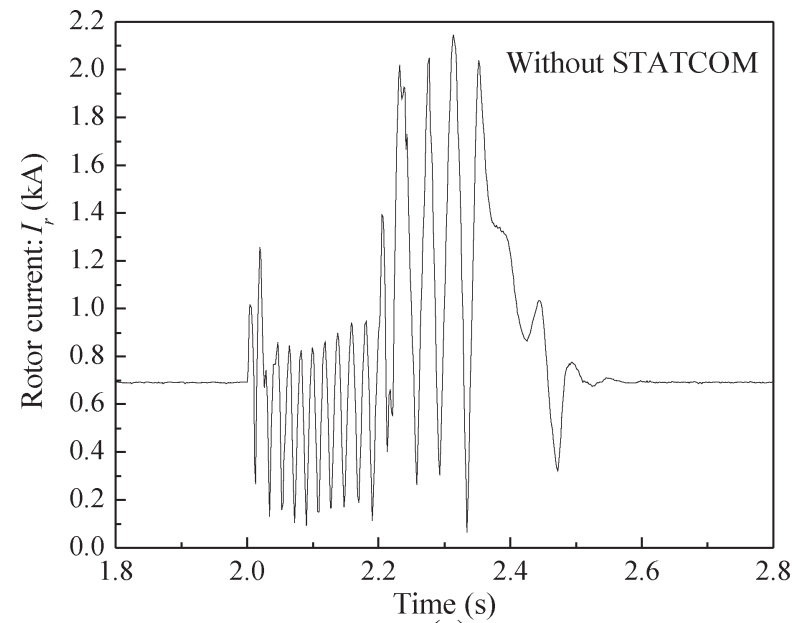

(a)

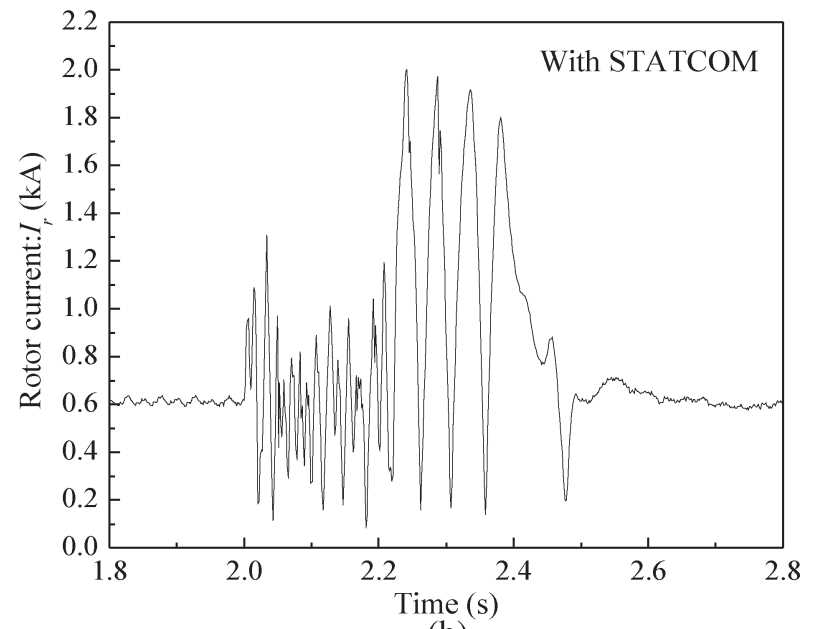

(b)

Fig. 10. RMS rotor current $I_{r}$ during a 200-ms three-phase short circuit at the infinite bus, RSC not blocking.

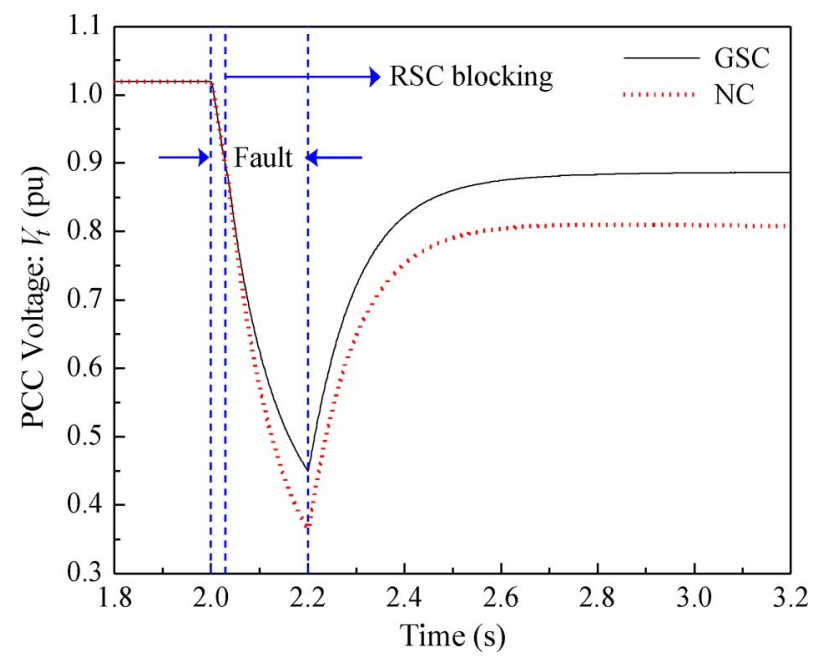

Fig. 11. 200-ms three-phase short circuit at the infinite bus, RSC blocking without STATCOM: PCC voltage $V_{t}$.

1.02 p.u. The fault is cleared at $t=2.2 \mathrm{~s}$. However, the PCC voltage cannot be reestablished without the STATCOM or by only using the GSC. Therefore, the RSC cannot restart, and the wind turbine has to be tripped from the system.

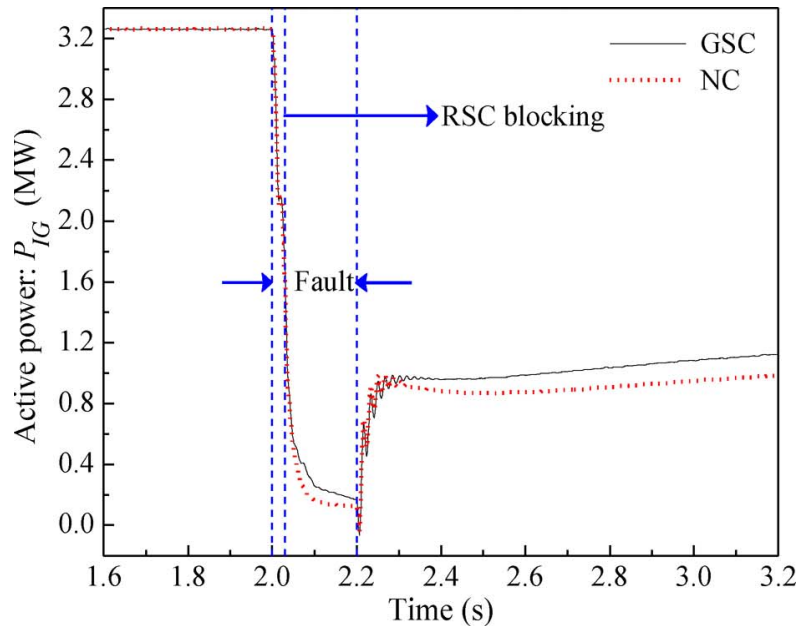

(a)

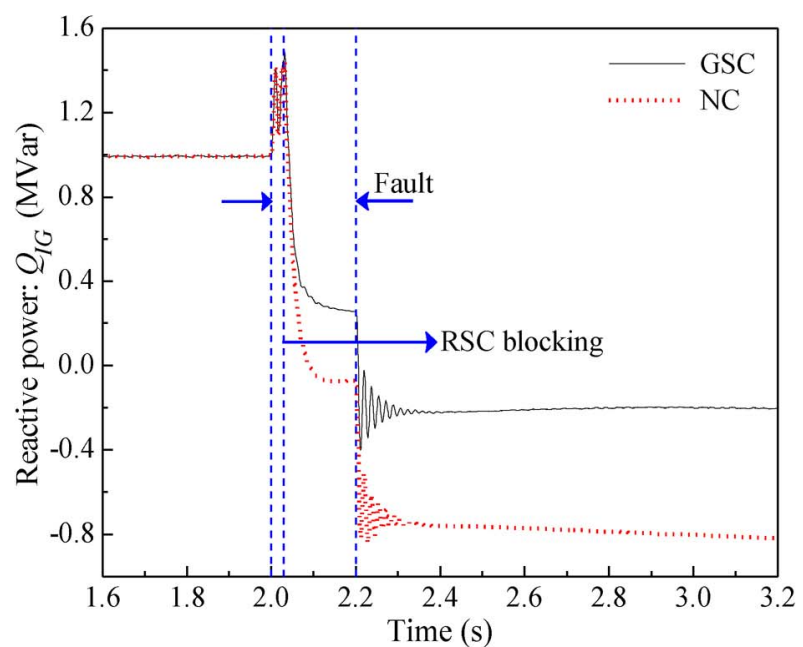

(b)

Fig. 12. 200-ms three-phase short circuit at the infinite bus, RSC blocking without STATCOM: $P_{I G}$ and $Q_{I G}$.

Fig. 12 shows the total active power $P_{I G}$ generated by the induction generator and the total reactive power $Q_{I G}$ exchanged between the induction generator and the grid. During the RSC blocking, the active power generated by the induction generator reduces significantly for both the GSC and the NC. After the fault has cleared (at $t=2.2 \mathrm{~s}$ ) but with the RSC still blocking, the induction generator absorbs some reactive power (negative values in Fig. 12) from the grid. However, compared with the case of NC, with the GSC providing reactive compensation, the induction generator produces more active power to the power grid, and the reactive power absorbed by the induction generator is reduced.

\section{Uninterrupted Operation of the Wind Turbine With the STATCOM}

A grid fault in the power network can be temporary or permanent. A permanent grid fault is normally cleared by disconnecting the power line on which the fault occurs from the system. Line tripping reduces the operational and stability margins of the power system and hence results in a relatively weaker power network. Therefore, a permanent grid fault with 


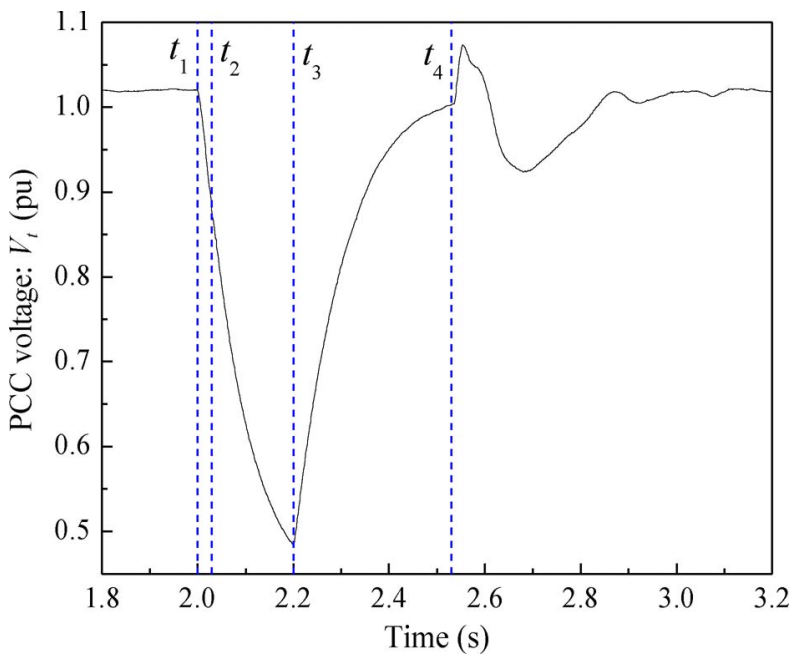

Fig. 13. Uninterrupted operation of the wind turbine with a STATCOM during a grid fault: $V_{t}$

line tripping is more severe than a temporary fault without any line tripping for power system operation and stability.

To demonstrate the effectiveness of the STATCOM to help the wind turbine ride through grid faults, a three-phase permanent short circuit is now applied to the receiving end of line 1 at $t_{1}=2 \mathrm{~s}$ and is cleared by tripping line 1. The STATCOM is now used to help achieve the uninterrupted operation of the wind turbine. During the entire test, the reactive power command of the GSC is set to $Q_{g}^{*}=0$. Fig. 13 shows the voltage profiles at the PCC. Before $t=t_{1}$, the power system is at normal operation. Thirty milliseconds after applying the short circuit (at $t_{2}=2.03 \mathrm{~s}$ ), the RSC is blocked to protect it from overcurrent in the rotor circuit. Two-hundred milliseconds after applying the short circuit (at $t_{3}=2.2 \mathrm{~s}$ ), the fault is cleared, and line 1 is disconnected from the system. In contrast to the cases of no STATCOM, as shown in Fig. 11, with the STATCOM for transient voltage support, the PCC voltage is quickly reestablished shortly after the fault has cleared. When the PCC voltage returns to a predefined value, the RSC starts switching. Finally, $500 \mathrm{~ms}$ after blocking the RSC (at $t_{4}=$ $2.53 \mathrm{~s}$ ), the RSC restarts successfully, and the uninterrupted operation of wind turbine is achieved.

Fig. 14 shows the magnitude of the rotor current $I_{r}$. Compared with Fig. 10, the rotor current transient is significantly reduced. During the RSC blocking, the rotor current magnitude is within its limit value $(1.0 \mathrm{kA})$ by connecting a suitably selected external resistance to the rotor circuit. In addition, with a proper restarting procedure and a suitably designed control system, the RSC successfully restarts with only a small transient in the rotor current.

Fig. 15 shows the total active power generated by the induction generator $P_{I G}$ and rotor active power $P_{r}$. During the RSC blocking from $t_{2}$ to $t_{4}$, the total active power generated by the induction generator is reduced, and there is no active power flowing through the rotor circuit $\left(P_{r} \approx 0\right)$. However, compared with the results without the STATCOM in Fig. 12, with the STATCOM now connected, the induction generator generates more active power to the power network when the fault has cleared (between times $t_{3}$ and $t_{4}$ ).

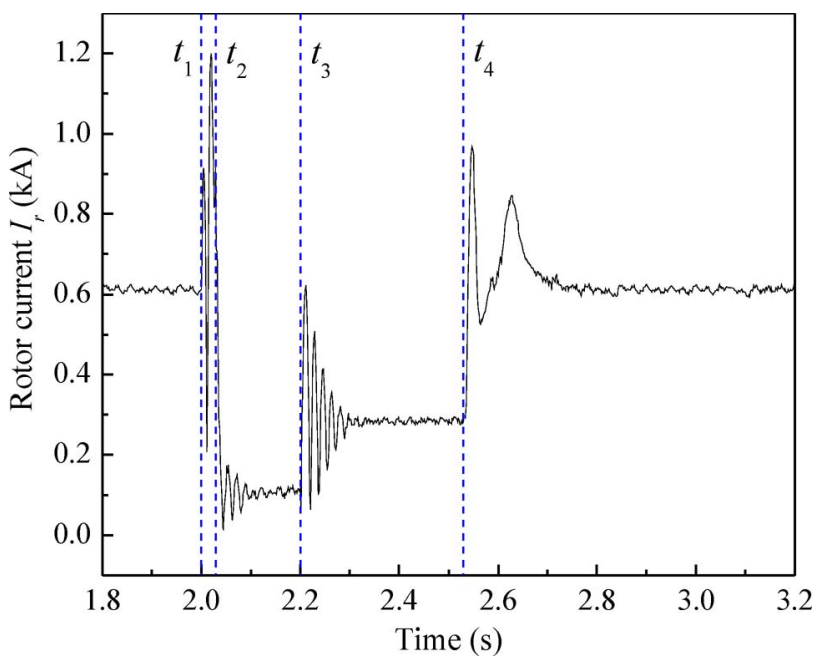

Fig. 14. Uninterrupted operation of the wind turbine with a STATCOM during a grid fault: $I_{r}$.

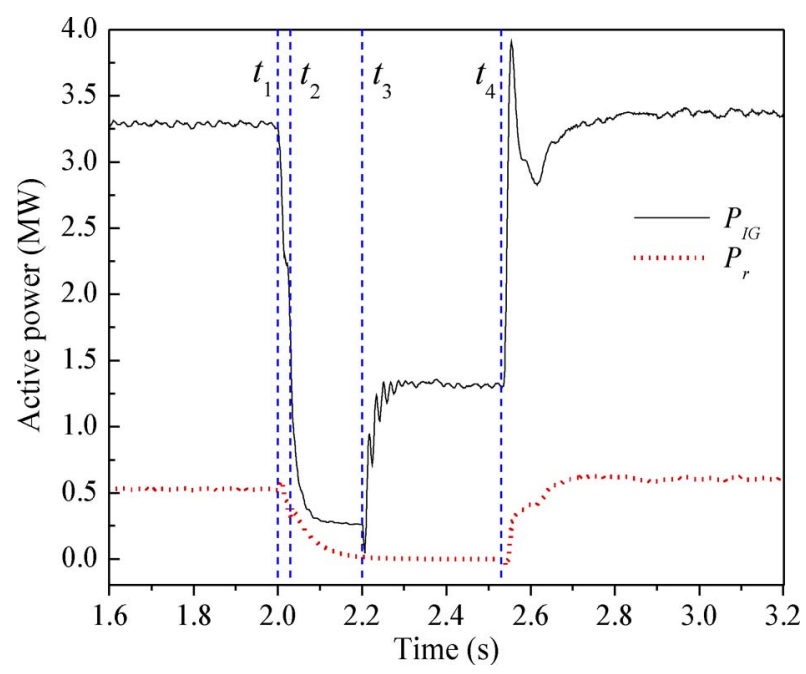

Fig. 15. Uninterrupted operation of the wind turbine with a STATCOM during a grid fault: $P_{I G}$ and $P_{r}$.

Fig. 16 shows the total reactive power $Q_{I G}$ exchanged between the induction generator and the grid, as well as the rotor reactive power $Q_{r}$. During the time period $t_{3}-t_{4}$ (the fault has cleared but the RSC is still blocking), the induction generator absorbs a large amount of reactive power from the power grid, and therefore, the use of dynamic reactive power compensation is required.

During the time period $t_{3}-t_{4}$ in Fig. 17, the RSC is blocked, and the STATCOM is providing 2.3-MVar reactive power. This could not have been provided by the GSC, which has a rating of 0.9 MVA, and underlines the need for a STATCOM or some other form of reactive compensation.

Another requirement for the successful uninterrupted operation of the wind turbine is the dc-link voltage stability of the VFC. As shown in Fig. 18, after the grid fault, the GSC controller successfully controls the dc-link voltage back to the nominal value of $4.0 \mathrm{kV}$. The overshoot of the dc-link voltage after $t_{4}$ when the RCS restarts, is less than $10 \%$ of the nominal value, which is a necessary condition for the RSC to restart. 


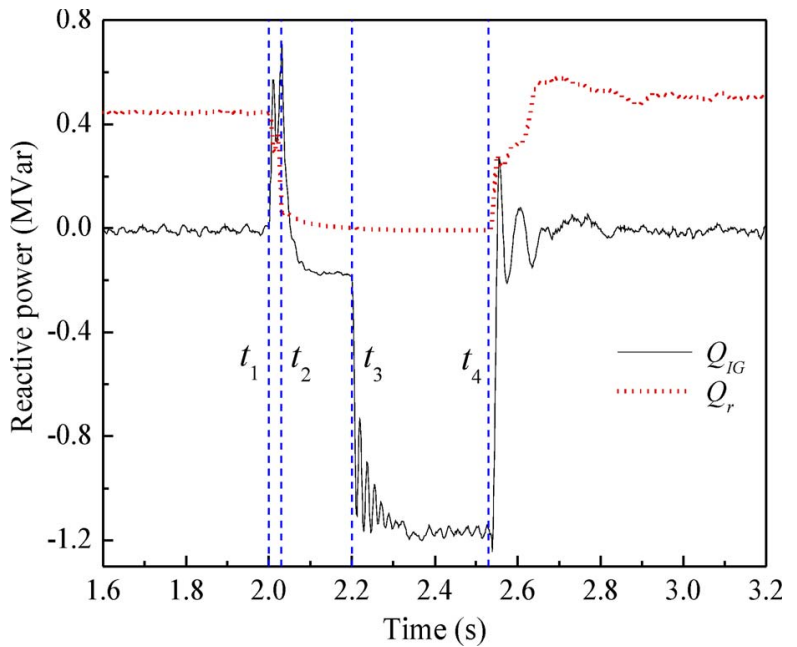

Fig. 16. Uninterrupted operation of the wind turbine with a STATCOM during a grid fault: $Q_{I G}$ and $Q_{r}$.

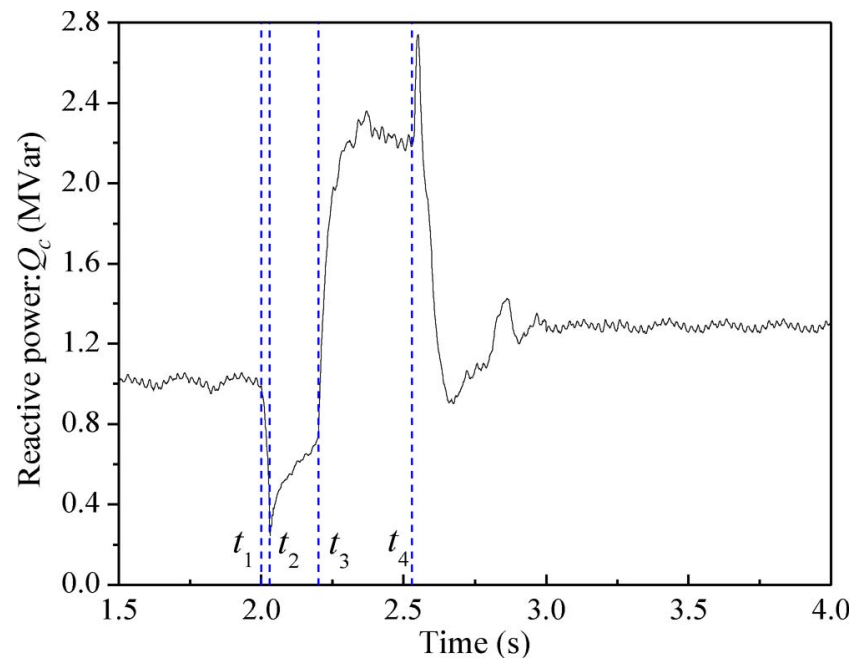

Fig. 17. Uninterrupted operation of the wind turbine with a STATCOM during a grid fault: $Q_{c}$ in Fig. 1.

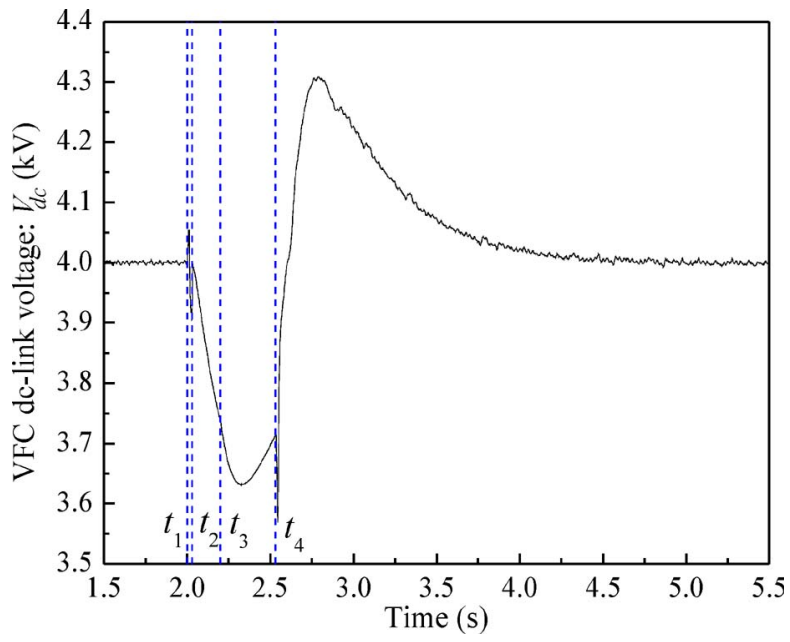

Fig. 18. Uninterrupted operation of the wind turbine with a STATCOM during a grid fault: $V_{d c}$.

\section{CONCLUSION}

The successful integration of wind farms to power systems might need dynamic reactive compensation to assist with voltage support, particularly during grid disturbances. This paper has investigated the application of a STATCOM to achieve the uninterrupted operation of a DFIG wind turbine during grid faults. The STATCOM is placed at the bus (PCC) where the DFIG is connected to the power grid, for steady-state voltage regulation and transient voltage support. The control schemes of the DFIG RSC, GSC, and the STATCOM have been suitably designed and coordinated.

The system has been implemented on an RTDS and subjected to short-circuit grid faults. During grid faults, the RSC is blocked and restarts when the fault is cleared and the PCC voltage is reestablished. Real-time implementation results show that with the STATCOM providing dynamic voltage support, the PCC voltage can be reestablished shortly after grid faults, and therefore, the wind turbine remains in service. However, without the STATCOM for voltage support, the PCC voltage cannot be reestablished after grid faults so that the wind turbine has to be tripped from the power network. The STATCOM improves the transient voltage stability and therefore enhances the grid fault ride-through capability of the wind-turbine generator system.

\section{REFERENCES}

[1] V. Akhmatov, "Analysis of dynamic behavior of electric power systems with large amount of wind power," Ph.D. dissertation, Tech. Univ. Denmark, Kgs. Lyngby, Denmark, Apr. 2003.

[2] R. Datta and V. T. Ranganathan, "Variable-speed wind power generation using doubly fed wound rotor induction machine-A comparison with alternative schemes," IEEE Trans. Energy Convers., vol. 17, no. 3, pp. 414-421, Sep. 2002.

[3] M. V. A. Nunes, J. A. Pecas Lopes, H. H. Zurn, U. H. Bezerra, and R. G. Almeida, "Influence of the variable-speed wind generators in transient stability margin of the conventional generators integrated in electrical grids," IEEE Trans. Energy Convers., vol. 19, no. 4, pp. 692-701, Dec. 2004.

[4] J. Morren and S. W. H. de Haan, "Ridethrough of wind turbines with doubly-fed induction generator during a voltage dip," IEEE Trans. Energy Convers., vol. 20, no. 2, pp. 435-441, Jun. 2005.

[5] M. Bruntt, J. Havsager, and H. Knudsen, "Incorporation of wind power in the East Danish power system," in Proc. IEEE Power Tech., Budapest, Hungary, Aug. 29-Sep. 2, 1999, pp. 202-205.

[6] N. G. Hingorani and L. Gyugyi, Understanding FACTS: Concepts and Technology of Flexible AC Transmission Systems. New York: IEEE Press, 2000.

[7] Z. Saad-Saoud, M. L. Lisboa, J. B. Ekanayake, N. Jenkins, and G. Strbac, "Application of STATCOMs to wind farms," Proc. Inst. Elect. Eng.Gener. Transm. Distrib., vol. 145, no. 5, pp. 511-516, Sep. 1998.

[8] C. Chompoo-Inwai, C. Yingvivatanapong, K. Methaprayoon, and W.-J. Lee, "Reactive compensation techniques to improve the ridethrough capability of wind turbine during disturbance," IEEE Trans. Ind. Appl., vol. 41, no. 3, pp. 666-672, May/Jun. 2005.

[9] N. W. Miller, W. W. Price, and J. J. Sanchez-Gasca, Dynamic Modeling of GE 1.5 and 3.6 Wind Turbine-Generators. Schenectady, NY: GE Power Syst. Energy Consulting, Gen. Elect. Int., Inc., Oct. 27, 2003.

[10] R. Pena, J. C. Clare, and G. M. Asher, "Doubly fed induction generator using back-to-back PWM converters and its application to variable-speed wind-energy generation," Proc. Inst. Elect. Eng.-Elect. Power Appl., vol. 143, no. 3, pp. 231-241, May 1996.

[11] A. Tapia, G. Tapia, J. X. Ostolaza, and J. R. Saenz, "Modeling and control of a wind turbine driven doubly fed induction generator," IEEE Trans. Energy Convers., vol. 18, no. 2, pp. 194-204, Jun. 2003.

[12] T. Tang and L. Xu, "A flexible active reactive power control strategy for a variable speed constant frequency generating system," IEEE Trans. Power Electron., vol. 10, no. 4, pp. 472-477, Jul. 1995. 
[13] C. Schauder and H. Mehta, "Vector analysis and control of advanced static VAR compensators," Proc. Inst. Elect. Eng.-Gener. Transm. Distrib., vol. 140, no. 4, pp. 299-306, Jul. 1993.

[14] V. Akhmatov, "Variable-speed wind turbines with doubly-fed induction generators. Part IV: Uninterrupted operation features at grid faults with converter control coordination," Wind Eng., vol. 27, no. 6, pp. 519-529, Dec. 2003.

[15] P. Forsyth, T. Maguire, and R. Kuffel, "Real time digital simulation for control and protection system testing," in Proc. 35th Annu. IEEE Power Electron. Spec. Conf., Jun. 20-25, 2004, pp. 329-335.

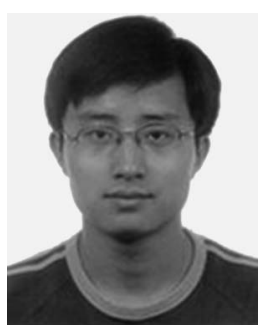

Wei Qiao (S'05-M'08) received the B.Eng. and M.Eng. degrees in electrical engineering from Zhejiang University, Hangzhou, China, in 1997 and 2002, respectively, the M.S. degree in highperformance computation for engineered systems from the Singapore-MIT Alliance, Singapore, in 2003, and the Ph.D. degree in electrical engineering from Georgia Institute of Technology, Atlanta in 2008 .

From 1997 to 1999, he was an Electrical Engineer with China Petroleum and Chemical Corporation (SINOPEC). Currently, he is an Assistant Professor of Electrical Engineering at the University of Nebraska-Lincoln. His research interests include renewable energy systems, distributed generation and microgrids, power system control, stability, and performance optimization, power electronics, electric machines, FACTS devices, and the application of computation intelligence in electric power and energy systems. He is the first author or coauthor of two book chapters and around 40 papers in refereed journals and international conference proceedings.

Dr. Qiao is the Technical Program Co-Chair of the 2009 IEEE Symposium on Power Electronics and Machines in Wind Applications. He was the recipient of the first prize in the Student Paper and Poster Competition of the IEEE Power Engineering Society General Meeting 2006 in Montreal, Canada.

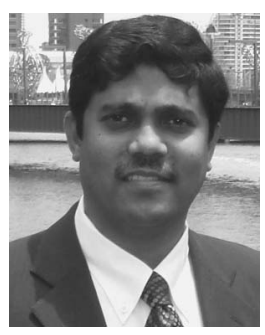

Ganesh Kumar Venayagamoorthy (S'91-M'97SM'02) received the B.Eng. degree (with honors) from Abubakar Tafawa Balewa University, Bauchi, Nigeria, in March 1994, and the M.S. and Ph.D. degrees in engineering from the University of KwaZulu-Natal (UKZN), KwaZulu-Natal, South Africa, in April 1999 and April 2002, respectively.

He was a Visiting Researcher with ABB Corporate Research, Vasteras, Sweden, in 2007. Currently, he is an Associate Professor of electrical and computer engineering and the Director of the Real-Time Power and Intelligent Systems Laboratory, Missouri University of Science and Technology (Missouri S\&T), Rolla. He has attracted in excess of U.S. \$4 million in competitive research funding from external funding agencies. He has published two edited books, five book chapters, 57 refereed journals papers, and over 200 refereed international conference proceeding papers. His research interests are the development and applications of computational intelligence for powersystem stability and control, alternative sources of energy, and flexible ac transmission system devices.

Dr. Venayagamoorthy is the Chair of the Working Group on Intelligent Control Systems and the Secretary of the Intelligent Systems Subcommittee of the IEEE Power Engineering Society. He is the General Chair of the 2008 IEEE Swarm Intelligence Symposium and the Program Chair of the 2009 IEEE-INNS International Joint Conference on Neural Networks. He was a recipient of the 2007 U.S. Office of Naval Research Young Investigator Program Award, the 2004 National Science Foundation CAREER Award, the 2006 IEEE Power Engineering Society Walter Fee Outstanding Young Engineer Award, the 2005 IEEE Industry Applications Society Outstanding Young Member Award, the 2003 INNS Young Investigator Award, and a 2007/2005 Missouri S\&T Faculty Excellence Award.

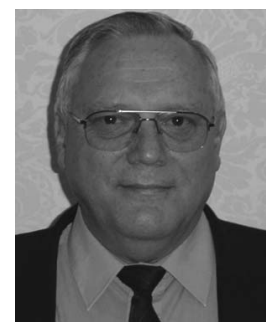

Ronald G. Harley (M'77-SM'86-F'92) received the M.Sc.Eng. degree (cum laude) in electrical engineering from the University of Pretoria, Pretoria, South Africa, in 1965, and the Ph.D. degree from London University, London, U.K., in 1969.

In 1971, he became the Chair of Electrical Machines and Power Systems, University of Natal, Durban, South Africa. He is currently the Duke Power Company Distinguished Professor with the School of Electrical and Computer Engineering, Georgia Institute of Technology, Atlanta. He has coauthored around 400 papers in refereed journals and international conference proceedings and holds three patents. His research interests include the dynamic behavior and condition monitoring of electric machines, motor drives, power systems and their components, and controlling them by the use of power electronics and intelligent control algorithms.

Dr. Harley was one of the IEEE Industry Applications Society's six Distinguished Lecturers during 2000-2001. In 2005, he was the recipient of The Cyril Veinott Electromechanical Energy Conversion Award from the IEEE Power Engineering Society. 